\title{
My Practice of Live Performance of Spatial Electronic Dance Music
}

\author{
Sebastien Lavoie \\ University of Huddersfield, UK
}

How to cite this paper: Lavoie S. (2019). My Practice of Live Performance of Spatial Electronic Dance Music. The Educational Review, USA, 3(7), 67-74.

http://dx.doi.org/10.26855/er.2019.07.002

*Corresponding author: Sebastian Lavoie, University of Huddersfield, UK.

Email: sebastien.lavoie.1@gmail.com

\begin{abstract}
In this commentary I will discuss the technical implementation of sound spatialisation in EDM (electronic dance music) performance practice and outline my compositional approaches involving these techniques. The use of space as a musical parameter in EDM is becoming more common as the accessibility of the technology increases. The technical means of performance and the sonic material combine to create a unique musical aesthetic and listening experience in EDM culture. An historical overview of compositions using spatial considerations as a main musical parameter will situate my work within this artistic practice. Different implementations and propositions of sound spatialisation, as well as the principal locations dedicated to this form of activity will be discussed to contextualise my work.

A fundamental part of my research concerns the use of spatialisation tools and techniques to enhance EDM through an immersive sound experience. Concepts and notions of musical 'flow' and live improvisation have shaped this research and the compositional and performance aesthetics that have come to underpin my creative practice. Furthermore, the idea of immersivity and the sublime have informed my compositional thinking, and this will be assessed in relation to my objective to create an enhanced listening experience in my live performances. A discussion of the blurred roles of composer/producer/performer will demonstrate how I consider my live performance practice to redefine what a composer of EDM can be. Thus, I consider this research to propose a viable model for modern EDM composers.
\end{abstract}

\section{Keywords}

Spatialisation, Sound, Electronic Dance Music (EDM), Performance, Binaural

When I compose music using spatialization techniques, I am aiming to create a sense of immersion and movement. I am enthralled by the ability and possibility to move sound in space and I consider it an important feature of music. For me, it enhances the listening experience, and this is achieved through localization, diffusion, height and trajectories of sounds. The implementation of spatial counterpoint in my compositions utilises parallel and contrary spatial motion. This use of spatial counterpoint inherently implies a set of compositional considerations for approaching a new work. My music is different to more typical electronic dance music (EDM) since we can hear sound trajectories, changeable rates of speed in sonic movement, localization and a height dimension in the sound. I have arrived at a heuristic meaning and common sense sets of rules for spatialization. This is my spatial counterpointal system for this practice: I have called it 'gravitational spatialization'. Essentially it comprises a spectral separation of the audio content with sound positioned according to its frequency.

As a young composer, my first works were created with my own recordings of concrète material "objets sonores" (Schaeffer, 1956, p. 62). These audio files were in a stereo format put into organized sound compositions. The premiere of my first work at an acousmatic concert provided the initial impetus for my discovery of electronic music in space as it was performed over a sound diffusion system which allowed me to spatialize my composition with an orchestra of loudspeakers. This newly acquired awareness expanded my musical horizons; I thought this dimension was to be an important aspect of my future in music. Acousmatic music concerts offered me insightful lessons during my musical progression and the art of diffusion became a prime focus throughout these formative years.

As my thinking and knowledge about working with sound in space developed, the next logical step was to compose works 
on a surround setup of speakers in order to create pieces containing recorded (fixed) spatialization, ready for performance. Accessible and intuitive tools to implement and to record spatialization in my compositions such as OctoGRIS, enabled me to create works for a surround array of eight speakers. This skill of writing sound in space became my preferred mode of expression and creation. I believed the experience of an acousmatic environment was an important and forward-thinking musical advancement for the contemporary artist.

I started to go to nightclubs at the age of fourteen years old and I grew up listening to Dance Music, which at the time (around 1988) coincided with the birth of House Music. Over the years, I have acquired knowledge from these music genres by regularly attending events of this kind and I have developed a strong inclination for rhythmical music, especially EDM. Unfortunately, most of them do not utilise the art of spatialization in any significant way. This is where I thought I could reconcile my musical aspirations: incorporating my skills from acousmatic composition and implement them in an EDM style. I started as an acousmatic composer and I became a composer/performer. I have developed a studio practice, where I want to integrate live performance and in-the-moment decision making at every point. My upbringing in nightclubs was dedicated towards the physical aspect of life. I relate this to my on-going need to experience music viscerally when I compose, and although I had a rigorous training in it, I do not find this sense of physicality in much of the acousmatic repertoire. Since, I have always been drawn to EDM, I started to apply my acousmatic practice to these styles of music production.

\section{In this project, concerning the spatialization of EDM, the research questions I posited were:}

- What role can spatialization play in EDM?

- How can I bring acousmatic experience into EDM to enhance it as a performative and compositional genre?

- How can creative work merge composition and improvisation?

- How can live performance practice redefine what a composer of EDM is?

- How do I achieve this through notions of 'gravitational spatialization', immersion and the idea of the sublime?

These questions affect my work as a composer, my role as a performer, and they also influence my sense of flow. Furthermore, this interrogative process made me research the idea of immersivity and the sublime, which have informed my compositional thinking. Through my particular compositional practice, I mix Techno, House and Trance music. I also define how my composer/producer/performer interchangeable roles work seamlessly as it is an interesting creative model. I have explored through the evaluation of spatialization tools and plugins, which ones would be relevant to implement to EDM.

In any discussion of my practice as research, I consider it important to question what differentiates my music from a normal DJ set. Firstly, I regard my works as compositions. They do however, contain long stretches of improvisation and did my acousmatic works. In these earlier works that I created during my undergraduate and Masters study, I would select materials that I thought could work together, and improvise with them in the studio. I would record all of my improvisations and then make a piece with these elements. Essentially, I am doing this now in real time; I create material that form the opening of my piece and through controllers, the Ableton Push 2 and Novation Launchpad Control XL (see Figure 1 below), I improvise with these materials using filtering, reverberation and shuffling effects in order to create a new section of the piece in real time. To demonstrate this creative process, in my piece Stix (2017), at 3'40", there are sonic transformations occurring on the original materials with heavy filtering, which makes the music nearly disappear until all the loops return with a different rhythm, created by using the shuffling effect. That similarity of practice is important, though I do not do the same thing in every piece. I either have a planned structure for my piece or, I develop my pieces as a logical stream of interlocking ideas that have a forward sense of flow to them. Compositional strategies I employ include applying an identical rhythmic pattern to all the loops, or expanding the sonic space by adding reverb to all the sounds or the speed of movement of these sounds. All of my pieces have a particular set of sonic materials that is unique to them. There is a lot of selection of sonic materials and thinking about space behind my compositions. For instance, Not The Last One (2017) contains mainly sounds similar to pink noise, and this provides a greater cohesion between all the sonic material, especially at 2'23”. My compositional approach is bound to the sense of flow: letting the materials potential steer the form and structure of my pieces.

There is a preparation, a selection, and a structure to each of my performances; I organize the set list and program for each specific event. The experimentation is done as the performance evolves, reading and sensing the components of that moment in order to provide the required musical offering:

When an EDM producer (usually also a DJ) in a recording studio selects and organizes sounds in determined ways, he is already acting in accordance with their virtual effects on a dance floor. Experimenting with sound combinations, he is also experimenting with his audience's movements, thus producing a kind of tool that comes from and arrives at his relations with the dance floor (Ferreira, 2008, p. 18). 


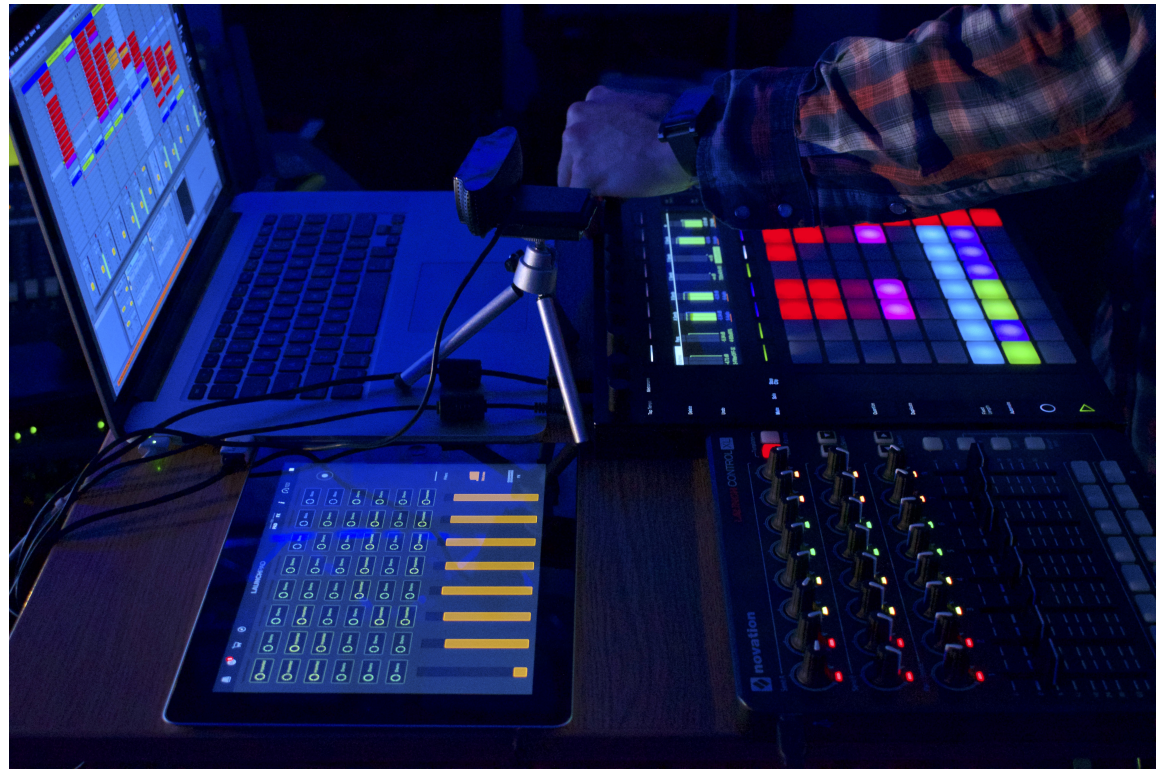

Figure 1 - Performance setup during Livestream events; Laptop using Ableton Live in conjunction with the Push 2 and the Novation's Launchpad Control XL, plus an iPad using Launchpad app in order to operate transitions from one piece to another in Live, 2017.

Thus, there are similarities between the act of DJing and my live performance. They both are organized in advance, but they also allow the freedom to improvise with the already composed musical material. What differs is my ability to decompose and recompose certain parts from the pieces as they unfold. In addition, I can apply specific effects on individual loops, which allows me to generate new musical ideas and directions to develop during the improvisational sections. Although, Pedro Peixoto Ferreira writes that:

This is not to say that there is no experimentation in EDM, only that it is not usually focused on the artistic creation of musical forms but rather on the technological modulation of the sound-movement relation. In other words, EDM is not a kind of creative message sent by a performer to his audience, but the sonorous dimension of a particular collective movement (Ferreira, 2008, p. 18).

In my work I do consider my method of formal arrangement to be a form of experimentation into what a track or composition can be. I want the experience to be an immersive one that can be appreciated both by the body and the head.

The conception of a website as the ultimate product of this research is a suitable form to transmit and share this project. Therefore, I have built my own webpage ( $\underline{w w w . S e b a s t i a n D e W a y . c o m})$ to store and share information regarding the progression and development of my music. It is a suitable platform to inform and teach people about music since it reaches our different senses; we can read about music in the form of a text, we can see performances visually, we can hear recording of compositions. All of these digital formats (text, video, sound) are presented on my website with hyperlinks, to gain further insight into the research. The website is a more accessible and involving resource for the propagation of music.

This research concerns the spatial presentation of EDM. I found that spatiality aids the perception and the comprehension of music, and I will explain why I use multichannel spatialization techniques when I compose. I then contextualize the idea of writing sound in space referencing significant composers and also the theoretical advancements and the technologies related to it. To illustrate the importance and valuable consideration that academic and commercial environments have offered towards spatialization, I have assessed some important locations and systems that focus on the art of spatial sound. I discuss how software and hardware tools affect my workflow and I will share the performance setup I have developed in order to unite spatialization and EDM in my work. In my complete research, I will contribute some observations on how I create binaural mixes of my compositions for headphone listening.

In the second chapter of the completed research, I discuss how I consider the act of composing as a performance. My pieces utilise two basic structural methodologies: working with a pre-conceived structure that leads onto a more improvisatory framework or starting with the improvisation itself and then slowly letting the pre-conceived structure emerge from this.

When I consider improvisation in my work, it is set within defined musical boundaries of time and rhythmical patterns. The application of improvisation in my work is limited in its scope, especially if I compare it to a musician such as Evan Parker with his electroacoustic ensemble, who exploits a larger spectrum of sonic and temporal possibilities when playing. He performs without any rules beyond the logic or inclination of his musical state, whereas what I play stays within the EDM genre. 
My style of improvisation relates more toward the model of the Big Band era of the 1940s and early 1950s, for instance Benny Goodman or Glenn Miller, which relied more on arrangements that were written or learned by ear and memorized. Thus, my pieces are composed and structured but also include moments where I, as a soloist, improvise within these arrangements. As a Big Band would, I also interpret pieces in individual ways, never playing the same composition in the same manner twice. Depending on the mood, experience, and interaction with the audience, melodies, harmonies, and rhythmical patterns develop and change from one performance to the next.

The idea of rhythm and dancing has been important throughout my life and over several years I attended numerous nightclubs in order to hear DJs during the 'golden age' of House and Techno music. The instant somatic gratification from the bass frequencies was compelling. Yet, I was also drawn to the compositional and intellectual aspects of this music. I find a parallel in the writings of Arthur Bissell when he is describing the primary perceptions and expectations of an artist during a performance:

The pleasure ... arises from the perception of the artist's play with forms and conventions which are ingrained as habits of perception both in the artist and his audience. Without such habits ... there would be no awareness whatever of the artist's fulfillment of and subtle departures from established forms ... But the pleasure which we derive from style is not an intellectual interest in detecting similarities and difference, but an immediate aesthetic delight in perception which results from the arousal and suspension or fulfillment of expectations which are the products of many previous encounters with works of art (Bissell, 1926, p. viii).

During the first year of this research, I produced some fixed media work that attempted to bridge these different styles of composition: the academic and more commercial music. For me, these pieces lack the sense of physical and intellectual fulfillment that I am looking for when I create work. Consequently, throughout the following experimentations, I concentrated my compositions towards live performance that includes my concept of 'gravitational spatialization', which is a positioning according to the frequency content of my sounds. Furthermore, I realized that sitting down at a concert was not my preferred mode of listening and because I like to move, and I like to hear the sounds moving as well, this form of embodied listening propelled me to search for a new way to perform and experience my music. Ultimately, my objective is to have a self-awareness of what it is I am making musically, where it is drawing from, and to demonstrate that what I am doing is synthesizing those key characteristics into something that is compositionally my own.

One of the things that I have realised while undertaking this research is the idea of multiplicity in my work. As an example, my music cannot be only described as a simple river of musical flow, neither as a massive ocean of music, ultimately my music has characteristics from both. In French, there is a term that describes the natural flow of water that crosses an area of land between a lake, river and ocean; it is called Fleuve. Thus, a Fleuve can be narrow enough to be considered a river and connects to a lake, and it also has the grandeur to reach the ocean. The Amazon River is one of the most important (Fleuve) rivers in the world; it occupies that multiple role of being small enough to be a river but large enough to reach the Atlantic Ocean. Similarly, my music can be pleasing to the 'outside' institutions (nightclubs), as well as the 'inside' establishment of academic music (universities). It contains hedonistic and visceral sonic qualities, but it can also intellectually stimulate the educated musical ear. The same applies to my compositional methodology: Is my work an improvisation or is it a structured piece? It is actually both; at different times it can change, evolve, progress without boundaries.

My work as a composer-producer is not bound to the studio, and the live performance is not the remix of my music. There is a triangulation, a symbiotic relationship between the studio work, the live performance and the final product (piece) that is essential to my methodology. All of these feed into each other. There is a continuous loop between them, a flow of musical direction going back and forth among them. As such, none of my pieces exist in a final form, they essentially become the sounds of a tool kit. I do not see any distinction between the roles of composer/producer/performer. These are not relevant distinctions for me, as there is a relationship between them that creates the ideal environment for me to make music. This inventive immersion, for me as an artist, is important to engender the creative flow, which has helped me to be prolific over the last two years of this research.

The way I compose and perform is through musical structure, process and intuition. The key compositional elements are the gradual accumulation and fragmentation of texturally and rhythmically driven loops. These elements help me to create a sense of musical flow through the 'emergence' and 'disappearance' of sonic content. The sense of flow is important for me when I compose, create or perform because it is organically evolving, transforming and changing what is happening musically. It allows me to have a vivid awareness, which enables me to react, respond and adapt to the music. It also allows me to reach an elevated state of consciousness in- and of-the-moment.

The concept of creative flow is considered in detail in Chapter Three of the completed research. I elaborate on psychologist Mihály Csíkszentmihályi's theories of 'flow' (1990, 1997). In them, he describes 'flow' as being in the zone, "in a mental state of operation in which performing is an activity where we are fully immersed in a feeling of energized focus, fully involved, and enjoying the process of the activity" (Csíkszentmihályi, 1990). Thus, I connect his theories to what I am trying to do both musically and aesthetically; not just about the mechanics of it, but also how I want to involve the audience in it. Furthermore, as a composer, I want to integrate concepts of immersivity and viscerality in order to reach the sublime in music. 
Among the characteristics that I consider important when composing is the immersive quality of the music. This immersion is related to the enclosed space where an array of speakers is the vehicle to convey the spatialization and the musical gesture to 'transport' the audience during a performance. Ultimately, I want the audience to experience a sense of immersion within the concert space, and through articulation points to make them aware of the musical structure. In addition, viscerality is another concept that is included in my work. It is achieved through immersion, the use of low frequencies and 'gravitational spatialization'; it is a phenomenon that emerges from all the actions I take when I perform my music.

One of my musical aims aspire to use an immersive sonic environment to create a three-dimensional audible experience. New media artist and theorist, Frances Dyson (2009), also investigated the significance and implication of immersion in her book Sounding New Media writing that:

The experience of this immaterial, simulated "space" operates through "immersion" - a process or condition whereby the viewer becomes totally enveloped within and transformed by the "virtual environment." Space acts as a pivotal element in this rhetorical architecture, since it provides a bridge between real and mythic spaces, such as the space of the screen, the space of the imagination, cosmic space, and literal, three-dimensional physical space. Space implies the possibility of immersion, habitation, and phenomenal plenitude (Dyson, 2009, p. 1).

Her notion of immersivity, however, is more related to the immaterial, intangible dimension of life, which is quite opposite to my desire to 'touch' viscerally (almost physically) the listener with my music.

When I perform live EDM, I want to achieve greater expression in my work rather than offering a passive acousmatic sound diffusion. Additionally, a way to accomplish the expressive sublime in my music is through the idea of immersion. The concept of immersion within my work is produced in the studio and it becomes a reality during the performance when using an array of speakers that surrounds the audience. Composer Simon Emmerson (2007), elaborates on ideas of new spaces and perspectives in regards of immersivity in a live performance:

Two new kinds of listening spaces relying on technology for their sound systems emerged from the 1960s to the 1990s. Both are totally immersive, but one is large and public, the other small and private. First the spaces of leisure listening, increasingly with the participation of dance, group encouraging and inclusive; secondly the space of the 'personal stereo', individual and exclusive. [...] The image is here totally immersive, designed to envelope, to create a total space into which intrusion of extraneous sound is impossible, not because it is excluded but because it is masked. The image is close, surrounding and omnidirectional, possessing a kind of amniotic reassurance (Emmerson, 2007, p. 103).

Immersivity has multiple theoretical aspects that are explored by Emmerson (2007), but for me it is really about being surrounded by sound. There is not one sonic point of origin, the listener/dancer is in the middle of it (the speaker setup) and the central position (sweet spot) is not important since people are moving and changing positions while they are dancing. For me, immersivity is where the body is engulfed in an overwhelming feeling of sonic presence. I concur with Emmerson's idea of the performance space being the ultimate listening environment: "These spaces were always there [...] but have now become more fully integrated into the 'total' experience" (Emmerson, 2007, p. 116).

I compose my music in a particular kind of way, where I use a certain type of reverb to give an artificial sense of distance. I work with the sense of length and scale, and I use multiple speakers to create that sense of immersion in that live space. It is not an imaginary landscape, but it is leading to the idea of the sublime in music, where I am imagining something that is physically imposing. When composing, I envision my music playing in a massive warehouse, crowded with people, with the sound coming from all around me. Part of the musical experience is when we let our ego depart from reality, not thinking about trying to imagine things but to be immersed in the physical senzation of the music and the sonic qualities 'in-the-moment' that are giving pleasure. In my music, I am trying to conjure something that is large scale and monumental, that is beyond human scope in order to create the idea of the musically sublime. I am doing this through playing with high volume, a wide frequency spectrum and a large number of loudspeakers in order to reach the intended sonic result.

One of the most important aspects of what I am doing is creating a sense of the sublime both for me as a composer/performer and the audience. The definition of the sublime that I am using is finding roots in classical antiquity, specifically in the influential first-century Hellenistic treatise the Peri Hupsous, attributed to Dionysius Longinus. Longinus concerns himself with the emotive force of the sublime as a moral agent, as a persuasive power to move and better the mind.

In my compositional quest, there is always this consideration to create, for me and the audience, something that is almost awe inspiring, as with the idea of the sublime. I am not aiming to make nice landscapes that are beautiful, I am endeavoring to create epic mountains, hence oriented towards the concept of the sublime. This is the aesthetic intent of my music; to be massive, impactful, almost symphonic in scale. I want to take the audience on a journey, not a physical or mental one but an emotional sublime experience.

The idea of the sublime in my music refers more to philosophical aesthetics than to solely musical terms. The notion of the sublime I refer to is Kantian in nature (2007, p. 51): such as having vertigo, like teetering on the edge, where the ego disappears. It is the idea that people are involved in an experience in which they get carried along with the flow of the music 
that I am creating, to such an extent that their own ego, and their own perception of the music becomes less important, they are immersed in this experience where they become one as a whole collective.

In my music, there are powerful and visceral - somatic (bodily) booming sounds, not simply a pleasurable (beautiful) sonic content, it relates to the idea of the sublime in the philosophy of art. In aesthetic theory, "a more classical conception of beauty might claim that something is beautiful because it is a correct and coherent arrangement of parts into a whole". A piece of music is beautiful because all the elements within it fit together creating a perceived sense of good balance and continuation or flow to form something pleasurable. Unlike the beautiful, the sublime is impressive and awe inspiring.

The sublime usually includes the impression of an object which can be fearful but does not inspire fear at that moment. Philosopher Immanuel Kant conceived of the sublime as "the power of reason over nature" (Kant, 2007, p. 51). His description of the dynamic sublime falls in line with Edmund Burke's conception; "it is the ability of reason to overcome the feeling of fear that we get from seeing something which can be dangerous but poses no current danger" (Burke, 1958, p. 69).

Thus, the beautiful elicits positive responses or emotions to sounds, while the sublime manifests unease or distress often followed by pleasure having realised that the sounds are not something which pose an immediate danger. My composition So It Goes (2017) includes instances of sonic intensity (at 22'22" and 23'18"), where the musical climaxes can sometime sound powerful and be overwhelmingly intense but there will be a release of sonic activity and a return to calmer moments. This musical crescendo and decrescendo connects to the idea of the sublime; facing the exhilaration of reaching peaks without falling off the cliffs, or the fear of stumbling down deeper into the valleys.

My work plays with these ideas of sonic puissance but also, it offers peaceful and exquisite musical transitions in order to reach the sublime. This is echoed in Kiene Brillenburg Wurth's thesis on The Musically Sublime (2002):

it is to say that the particular structure of Kantian sublime experience parallels the structure of the process of sublimation in so far as a 'negative' feeling of frustration or terror (pain) is removed and transformed into a 'positive' feeling of delight or elevation (pleasure). What happens in the Kantian sublime, I will explain, is that an initial, apparently unacceptable awareness of self-limitation (manifested as frustration or terror) is resolved - removed and sublimated into a delightful, psychologically more welcome, realization of one's own supersensible power and limitlessness. In the end, the Kantian sublime experience is thus never truly disturbing but rather reassuring: any feeling of helplessness, frustration, or fear, any self-undermining senzation, in all its negativity, promises (if not already implies) a positive 'result' of self-affirmation and self-elevation exorcising that very frustration or fear (Brillenburg, 2002, p. xx).

Additionally, the sublime in my music is achieved through the 'flow' that provides the extension and duration for my piece to get longer, as with stream of consciousness. Traditional musical syntax is almost overturned; the sense of musical timing is very much extended; my tracks last between 15-20 minutes. My compositional process is not simply short piece after short piece, it has long flowing, almost symphonic lines of sounds, perhaps being lost musically, structurally within that. In this approach, we are carried along as a listener on the surface of the music, but the understanding of the musical structure is practically impossible to perceive because of the length, of the changes and transformations that occur, and also because the musical phrases are continually developing or evolving. My music is not structured like a conventional EDM track, or a verse and chorus pop format in which the listener can more easily orient themselves. There are musical materials that do come back, but they do so in an organic manner. This organic quality lends itself to achieve the sublime as there is a sense of order, but it cannot simply be predicted by the listener.

My compositions relate to an idea developed by Adam Krims (2000) regarding a sublime musical aesthetic, where "the result is that no pitch combination may form conventionally representable relationships with the others; musical layers pile up, defying aural representability for musically socialized Western listeners" (Krims, 2000, p. 68). According to his article, the idea can be described as the "hip-hop sublime". Thus, following Krim's representation of this musical style I suggest a "techno sublime", where it connects with the reality of its environment; in desolate and underground warehouses, which also suggest a figure for inner-city life that describes a post-industrial urban devastation.

We are reminded of Edmund Burke's formulation of the sublime. Burke goes on to describe the fear of being smashed by "unfigurable" power. [Techno sublime's] representation situates the listener in the geographical and social location from which capital's smashing power is most visible. In other words, [the Techno sublime] presents a view from [the destitute post-industrial rave parties] at the massive, unfigurable but menacing force of world capital (Krims, 2000, p. 72).

Conceptually, I relate my work to that of musician Jon Hopkins. In his piece Collider (2013), he plays with the sense of timing and change; it is not focusing on simple harmonies that slowly evolve, the layers do not coincide, and the harmonic layers grate against each other in order to produce a sense of inner rhythmic instability. These musical elements create a certain musical (physical) unease or disturbance that relates to this idea of the sublime in music.

The feel-good quality to my music can be interpreted as superficial (pleasant to the ears) but there is an intellectual questioning regarding what comes next in order to provide this musical continuum. The objective when I compose/perform is to feed into 
what sounds good to me and into different models of musical decision-making. The inter-relationships between the fast-paced rhythmic loops from my pieces mixed with the longer, reverberating sounds are playing with the concept of ebbing water; transitioning smoothly or not with current and new sonic materials. This methodology of composing is reflected in my music and is described in Jacques Attali's book Noise:

[Music] is more than an object of study: it is a way of perceiving the world. A tool of understanding. [...] Music, the organization of noise, is one such form. It reflects the manufacture of society; it constitutes the audible waveband of the vibrations and signs that make up society (Attali, 1976, p. 4).

In my research into the application of spatial technologies and techniques to EDM, in order to create immersive and sublime experiences, this is one way in which I use music to understand my place as an original creative person within society. The music is more than an object of study and technical implementation of compositional principles, it is a way for me to articulate how I express myself in the world.

Throughout this research, I have experimented with a range of software and hardware tools that allow differing spatial formats to be explored. From this, I was able to develop a methodology of spatializing EDM. I believe that the role of spatialization in EDM will continue to grow as nightclubs and academic institutions continue their developing interest in it. What is inspiring for me are the new tools and environments which are going to emerge and how I will be able to incorporate them into my practice. One of the areas that excites me is opened up by the Dolby Atmos plug-in and its application. This seems to suggest an exciting future, where the sonic experience is enhanced; it is an evolution compared to the current stereo standard in EDM. I was pleased to find out that the methodology I have developed, within the Ableton and Max4Live framework, was an easy adaptation with the Dolby tool since they function in a similar way; this demonstrates that the technology is evolving in the same direction and becoming more refined. This leads me to think that I am ready and prepared for what is next in the field of EDM spatial music because I know what works for me and how to achieve it. I am also enthusiastic about the fact that Dolby "is bringing its object-based 3D-audio platform to the dance music sphere by way of club installations and apps aimed at studio and DJ mixing" (Rothlein, 2015). They are also looking to expand the locations where their technology is installed. After London (Ministry Of Sound), Chicago (Sound-Bar) and San Francisco (Halcyon), clubs in Tokyo and Berlin are also on their radar. This encourages me to continue and to strive in that direction, in order to keep my knowledge and skills relevant. Also, I am curious to see what Ableton has planned with regards to the performance of multi-channel EDM. There are Max4Live objects in their latest software version (Live 10) that have implemented High Order Ambisonic libraries and a binaural tool which enables the user to play with Multi-Channel/Surround/Ambisonic audio.

As an artist I do think it is important that I need to push boundaries - doing it step by step while still accomplishing what I want to do musically. I want to continue to promote nightclub (commercial) music as being as valid as any other genre. I see a comparable evolution with Jazz music when it was considered an 'underground' phenomenon, not welcomed into academia, until it reached universal acceptance. EDM has followed a similar development entering progressively academic institutions as a subject of serious study. A parallel occurrence can be observed with the recent shift in perception of society in regard of graffiti artists such as Banksy, who did not have any other outlet than the street to display his art, and now is welcomed into galleries and other prominent art centers. This shows how something can exist outside the establishment and may become institutionalized. Thus, I want to elevate EDM to a noble art form in order to teach it, not just use it for commercials purposes only.

One of the reasons I have tackled this long academic endeavor was to push myself further as a musician in an evolving technological landscape. I was motivated to do it because I see a trend among the younger generation of music students: they often have not played traditional instruments such as a guitar, a violin or a piano, but most likely they own computer which has the potential to be a musical instrument. This coincided with my own situation, using the computer as a creative tool. In this research project, I have demonstrated that merging composition and improvisation can provide a rich creative environment for the composition and performance of EDM. Furthermore, I have established in this document that my live performance practices redefine what a composer of EDM can be. Thus, I want this research to promote a viable future for modern EDM composers. A way to share and develop these skills would be to teach at universities with computer music-based programs, as well as reputable institutions of EDM such as Point Blank Music School (London, Los Angeles, Ibiza, Mumbai, Online), Dubspot (New York, Los Angeles, Online) and The Red Bull Music Academy (Berlin, Online). As such, this commentary and portfolio presents a methodology and a set of accessible tools to be able to create music as a contemporary artist, while acknowledging the growing popularity of EDM and spatialization.

When I first encountered the SPIRAL Studio, I was intimidated by its size and its complexity. Since then, I have assessed various tools and techniques for spatialization and what changed most since the beginning of the research is the level of confidence I have acquired when approaching large speaker arrays. Also, since I am using accessible spatialization tools, I have developed a method to adapt quickly and easily to various configuration of sound systems.

Over the course of this research, I have learned ways to promote myself as a performer by growing a social media presence by livestreaming my music. Since July 2016, I have performed live on several streaming platforms such as YouTube, Facebook, Twitch, and Periscope; I have over 150 videos where I play music. This experience is an ongoing project and it allows me to 
improve my music on a technical and practical level. It is a practical outlet for me to mature as a performer and also to reach an audience around the world. I am looking forward to the day where spatial audio will be accessible in a livestreaming format since the technology is still being developed and not yet available. Until then, I am getting ready.

\section{Bibliography}

Attali, Jacques (1985). Noise: The political economy of music. Vol. 16. Manchester: University of Manchester Press.

Bissell, Arthur D. (1921). The role of expectation in music. New Haven: Yale University Press.

Brillenburg Wurth, C. A. W. (2002). The musically sublime: infinity, indeterminacy, irresolvability s.n. University of Groningen.

Burke, Edmund, and J. T. Boulton (1958). A philosophical enquiry into the origin of our ideas of the sublime and beautiful. 1967 reprint. ed. London: Routledge and Kegan Paul.

Csíkszentmihályi, Mihály (1990). Flow: The Psychology of Optimal Experience. New York: Harper \& Row.

Csíkszentmihályi, Mihály (1997). Creativity: Flow and the Psychology of Discovery and

Invention. New York: Harper Collins Publishers.

Dyson, Frances (2009). Sounding new media: Immersion and embodiment in the arts and culture. 1st ed. Berkeley: University of California Press.

Emmerson, Simon (2007;2017;2013). Living electronic music. Aldershot: Ashgate.

Ferreira, Pedro Peixoto (2008). When sound meets movement: Performance in electronic dance music. Leonardo Music Journal 18: $17-20$.

Kant, Immanuel, et al. (2007). Critique of judgement. New York; Oxford: Oxford University Press.

Krims, Adam (2000). The Hip Hop Sublime as a Form of Commodification found in Music and marx: Ideas, practice, politics. (2002) New York: Routledge.

Rothlein, Jordan (2015). A 60-speaker, 22-channel system will bring "an unparalleled music experience" to the main room of the long-running London nightclub. (https://www.residentadvisor.net/news/32448)

Schaeffer, Pierre (1959). Musique concrète et connaissance de l'objet musical. Revue Belge De Musicologie / Belgisch Tijdschrift Voor Muziekwetenschap 13 (1/4). 